due attention to the precarious status of this subpopulation to ensure it remains extant.

ANGELICO Jose C. TIONGSON (๔ orcid.org/0000-0002-09660756) Institute of Environmental and Marine Sciences, Silliman University, Dumaguete City, Philippines

E-mail angelicoctiongson@su.edu.ph

JEAN AsUnCION UTZURRUM (@ orcid.org/0000-0002-1606985X) Institute of Environmental and Marine Sciences, Silliman University, Dumaguete City, Philippines

Manuel Eduardo L. De La Paz Center for Research and Engagement, University of St. La Salle, Bacolod City, Philippines

\section{First steps towards conservation of the Endangered blonde capuchin monkey Sapajus flavius in the Caatinga dry forest, Brazil}

The blonde capuchin monkey Sapajus flavius is categorized as Endangered on the IUCN Red List (Valença-Montenegro et al., 2020, dx.doi.org/10.2305/IUCN.UK.2020-2.RLTS. $\mathrm{T} 136253 \mathrm{~A} 70612866$.en). The species was previously considered endemic to a narrow strip of the Atlantic Forest in north-eastern Brazil but has been reported in dry forest and has been observed in the Caatinga biome (Ferreira et al., 2009, Primates, 50, 357-362; Martins et al., 2016, 26th International Primate Society Congress, Abstract, 206-207). The Atlantic Forest and Caatinga biomes differ markedly in temperature, rainfall, humidity, availability of water bodies and vegetation structure. The Caatinga has a hot and dry climate with a dry season of more than 8 months, and its vegetation comprises low and small trees, with many shrubs and xerophytic species.

As the ecology and behaviour of the blonde capuchin monkey has only been studied in the Atlantic Forest, we are conducting the first study of the species in the Caatinga biome. We are exploring the demography, ecology and behaviour of a population of the blonde capuchin monkey in a dry forest fragment in the state of Rio Grande do Norte, north-east Brazil.

The first phase of the survey was conducted in JulyDecember 2019 when a group was monitored for 7 days per month. Although other species of capuchin monkeys are known to use tools (e.g. Sapajus libidinosus; Fragaszy et al., 2004, American Journal of Primatology, 64, 359366), this behaviour has not been reported previously for the blonde capuchin monkey in the Atlantic Forest. In the Caatinga, we observed sites with evidence of the

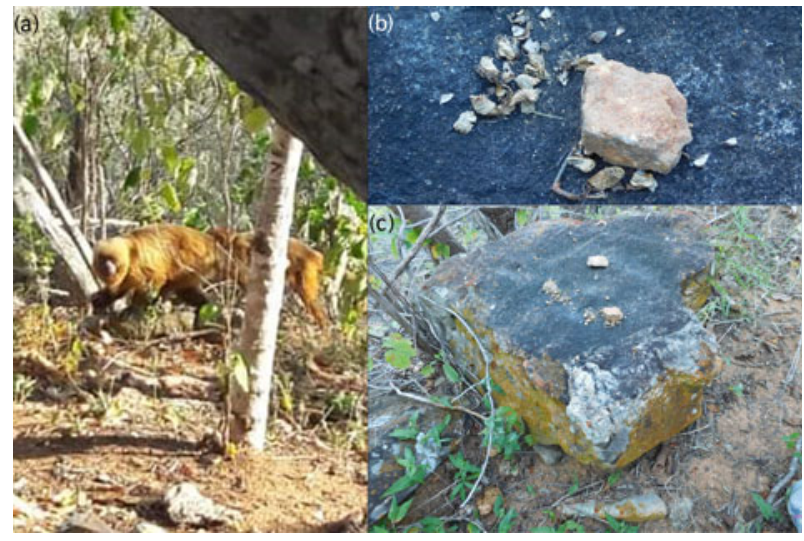

Plate 1 Blonde capuchin monkeys Sapajus flavius moving on the ground in the Caatinga biome of north-east Brazil (a), along with evidence of their use of hammer and anvil stone tools for opening Manihot epruinosa seeds (b), in the site denominated as 'tool use sites' (c). Photos: Aluízio dos Santos (a) and Francini Garcia (b, c).

use of stones for cracking nuts of Manihot epruinosa (Euphorbiaceae). Small stones were used as a hammer on larger anvil stones, and we found evidence of food items processed by this method (Plate 1). We also observed the species feeding on Pilosocereus pachycladus (Cactaceae) fruits, and commonly observed terrestrial behaviour, something that occurs only rarely in the Atlantic Forest.

Our study will continue for the next 3 years, collecting data to evaluate how the blonde capuchin monkey is adapted to this dry forest. We will also examine any potential threats to the species in the Caatinga and develop strategies and actions for the conservation of this primate and its habitat.

We thank Coordenação de Aperfeiçoamento de Pessoal de Nível Superior for a scholarship to FG, Fundação de Amparo à Ciência e Tecnologia do Estado de Pernambuco for a scholarship to JPS-A (BFP-0149-2.05/19), and the Primate Action Fund, which will support future research on this species.

FRANCINI GARCIA (o orcid.org/0000-0001-6811-4328) and JoÃo Pedro Souza-Alves (o orcid.org/0000-0002-8517-1276) Programa de Pós-Graduacão em Biologia Animal, Departamento de Zoologia, Laboratório de Ecologia, Comportamento e Conservação, Universidade Federal de Pernambuco, Recife, Brazil. E-mail francini.garcia@ufpe.br

AmELY MARTINS (ㅇo orcid.org/0000-0002-1200-4872) and MÔNICA VALENÇA-MONTENEGRO (10 orcid.org/0000-00016574-819X) Centro Nacional de Pesquisa e Conservação de Primatas Brasileiros, Cabedelo, Brazil 